\title{
El perfil sociológico de las diputadas del Grupo Parlamentario Popular en el Congreso de los Diputados (1986-2008)
}

\author{
Gema Sánchez Medero
}

Facultad de Ciencias Políticas y Sociología. Universidad Complutense de Madrid medero2000@yahoo.es

\section{Resumen}

En el artículo, se analiza el perfil sociológico de las diputadas nacionales del PP y se comparan con sus compañeras del Grupo Parlamentario Socialista. Por lo tanto, podremos exponer las características que presentan las mujeres del mayor partido de la derecha española, y así averiguar si siguen el mismo patrón que el de las socialistas. De esta manera, podremos demostrar que esta organización política, a pesar de no contar con un sistema de cuotas para garantizar la incorporación de la mujer, ha optado por la integración femenina de forma deliberada y planificada. No obstante, para verificar estos datos, se han analizado las siguientes variables: la composición de los grupos parlamentarios, y la edad, el nivel educativo, la ocupación, la experiencia en el partido y en los cargos públicos de los miembros de ambas organizaciones políticas.

Palabras clave: sistema de cuotas; partidos políticos; paridad; mujeres; política; género; Parlamento; Partido Popular; PSOE; Congreso de los Diputados.

Abstract. The sociological profile of female deputies of the Popular Party's Parliamentary Group in the Congress of the Deputies (1986-2008)

The article analyzes the sociological profile of the female national deputies of the Popular Party (PP) and compares it with their counterparts of the Socialist Parliamentary Group. As a result, we will explore the characteristics that present the women of the biggest party of the Spanish Right, and thereby find out if they follow the same pattern as the Socialists. Thus, we show that this political organization, despite of not having a quota system to ensure the incorporation of women, has opted for their integration in a deliberate and planned manner. However, to verify these data we have analyzed the following variables: the composition of the parliamentary groups, as well as age, educational level, occupation, experience in party and public offices of the Members of both political organizations.

Key words: quota system; political parties; parity; women; gender; parliament; PP; PSOE; Congress of Deputies. 


\begin{tabular}{|c|c|}
\hline \multicolumn{2}{|c|}{ Sumario } \\
\hline \multirow{4}{*}{$\begin{array}{l}\text { La participación de las mujeres en la vida } \\
\text { política: los sistemas de cuota }\end{array}$} & Las mujeres en el Grupo Parlamentario \\
\hline & Popular \\
\hline & Conclusiones \\
\hline & Bibliografía \\
\hline
\end{tabular}

\section{Introducción}

Existen pocos estudios politológicos que analicen el perfil sociológico propiamente dicho de las mujeres que han obtenido un escaño en la Cámara Baja. En España, además, existe un gran carencia de estudios académicos que aborden cualquier temática relacionada con las mujeres, aunque, en la actualidad, se está intentando solventar esta deficiencia con la aparición de una tímida producción literaria y una serie de investigaciones que han sido impulsadas principalmente por el Instituto de la Mujer o determinadas instituciones académicas. Hasta el momento, sin embargo, los estudios se están centrando en el análisis de la participación de la mujer en las instituciones políticas, pero no sobre sus características sociológicas. De ahí que, en este artículo, pretendamos hacer cuatro cosas:

1) Determinar qué características presentan las mujeres de un partido que no regulan de forma estatutaria ninguna medida para favorecer la incorporación de las mujeres en la vida política.

2) Averiguar qué prácticas ha llevado a cabo este partido para integrar a mujeres en su máximo ámbito de representación política, su grupo parlamentario en el Congreso de los Diputados, y así poder confirmar si éstas se corresponden o no con una política de «cuotas» encubierta.

3) Comparar el perfil de las mujeres de un partido sin cuotas y de otro que sí las aplica, para fijar las diferencias y las similitudes que existen entre unas y otras.

4) Contribuir, en España, al avance de este tipo de estudios dentro del mundo académico. Para ello, hemos acudido a los anuarios biográficos del Congreso de los Diputados, para, de esta manera, poder recopilar los datos sociológicos de todas las diputadas (altas y bajas) que han formado parte del grupo durante la legislatura y sobre las que se conformará nuestro análisis, es decir, la edad, el nivel de estudios, la ocupación y la experiencia en cargos públicos y políticos.

Los años seleccionados abarcan de 1986 a 2004, por ser el periodo de tiempo en el que Alianza Popular se refundó en el Partido Popular, y en el que en el PSOE se aprobaron las cuotas de participación femenina y la famosa Ley de igualdad. De esta manera, se podrá demostrar que incluso las fuerzas políticas que no han optado por una política deliberada de cuotas han llevado a cabo algún tipo de estrategia para incrementar la presencia femenina en la Cámara Baja. 


\section{La participación de las mujeres en la vida política: los sistemas de cuotas}

En la mayoría de los países, el derecho al voto ha estado restringido por razones de sexo, pero también, entre muchas otras causas, por: la condición de propietarios de los varones (voto censatario), la alfabetización, la etnia, la raza y las actividades que, por su naturaleza, eran consideradas contradictorias con la misma idea de ciudadanía, como el servicio doméstico. En el siglo XX, en la mayoría de los regímenes modernos, se instauró el sufragio universal, aunque sólo a finales de este siglo se ha logrado que más del 95\% de los países del mundo concedieran derechos democráticos a las mujeres, como son el derecho al sufragio activo y pasivo, es decir, el derecho a votar y a ser elegido. No obstante, pese a reconocérseles los mismos derechos que a los hombres, su participación política ha sido más bien escasa, si tenemos en cuenta el volumen de población que representan, aunque esta situación parece que se ha ido modificando a medida que la población femenina se ha hecho más activa y ha exigido a las elites políticas que presten una mayor atención a sus demandas, lo que ha obligado indudablemente a los partidos políticos a desarrollar tres tipos de estrategias para conseguir captar el voto de este sector de la población. La primera ha sido aceptar las demandas de las mujeres e incorporarlas en su discurso, además de reconocer públicamente la importancia de aumentar su presencia en la arena política. La segunda ha consistido en animar a las mujeres a participar más activamente en política. Y la tercera se ha centrado en potenciar las medidas que favorecen la discriminación positiva.

En este sentido, habría que decir que el sistema de cuotas de discriminación positiva se ha empleado para garantizar que el género femenino obtenga un mínimo de representación, aunque una buena parte de las elites políticas y académicas, particularmente las que se ubican ideológicamente más a la derecha, han presentado ciertas objeciones, incluso se han negado a aplicar este tipo de cuotas. Por considerar, que pese a ellas, todavía existen numerosas barreras que impiden a las mujeres alcanzar y ejercer el poder real:

Primero, porque todavía son muchas las mujeres que siguen teniendo la completa responsabilidad de las tareas domésticas y la crianza de los niños. Segundo, porque al ingresar en la escena política, muchas mujeres no tienen acceso a las tradicionales redes masculinas, lo que limita su habilidad para participar en las negociaciones y en las relaciones informales que tienen lugar detrás de las puertas cerradas. Tercero, porque para poder influir en el desarrollo económico, político y social de su país, las mujeres tendrán que continuar luchando para ganar acceso a comités y ministerios relacionados con la política exterior, la economía y las finanzas. Cuarto, porque algunas mujeres deberán superar las barreras ideológicas y psicológicas como los roles sociales asignados a mujeres y a hombres. (Buvinic y Roza, 2004: 18).Y quinto, porque no existe un verdadero interés en los partidos para concederles poder real.

En cualquier caso, la resistencia contra las cuotas ha sido tal que, en algunos países europeos, se ha trasladado al terreno de lo legal. Por ejemplo, en Italia, la sentencia de la Corte Costituzionale Italiana consideró inconstitu- 
cional una reforma legislativa que, en las elecciones municipales, obligaba a que cualquier lista electoral, del total de los puestos elegibles, hubiera al menos un 33,3\% de cualquiera de los dos sexos. En América Latina, Venezuela rescindió este mecanismo y, en México, el Partido Acción Nacional promovió, en diciembre de 2001, un recurso de inconstitucionalidad para impugnar las reformas electorales en Coahuila, mediante las cuales se pretendía impedir que más del 70\% de los candidatos fuera de un solo género (Ojeda, 2006: 41).

Pero, pese a todo, según los datos de la Unión Interparlamentaria de 1992, se contaba con 34 países que habían optado por el establecimiento de un sistema de cuotas, además de una serie de medidas para que éstas resultasen efectivas ${ }^{1}$. Hoy en día, son más de 100 los países que se han decantando por algún tipo de cuota, con lo cual, las acciones positivas parecen haberse convertido en una norma internacional creciente con respecto a la necesidad de promover la representación política de las mujeres (Krook, 2006a). Aunque la experiencia revela que el éxito de las cuotas de género dependen, en gran medida, de las características del sistema electoral, de la precisión de las normas que sustentan este tipo de medidas y de la activa participación de los actores nacionales en su instrumentación y vigilancia para su correcta aplicación.

Por tanto, el éxito de las cuotas viene condicionado por una serie de limitaciones, como pueden ser los sistemas electorales, ya que, como sostiene Rule (1994: 689): «las circunstancias sociales favorables no pueden superar el efecto de sistemas electorales desfavorables para la representación femenina». En este sentido, habría que mencionar que la mayoría de los estudios que se han realizado a este respecto afirman que este tipo de medidas consiguen mejores resultados en aquellos sistemas de representación proporcional de listas cerradas y de distritos de grandes magnitudes (Caul, 1999; Htun y Jones, 2002). En primer lugar, porque los sistemas proporcionales suelen presentar mayores magnitudes en cuanto a los distritos electorales y a la cantidad de cargos que un partido puede obtener en cada distrito. Así, cuanto mayor sea el número de escaños a repartir, más oportunidades tendrán las mujeres para salir electas en una determinada circunscripción, dado que, en las circunscripciones electorales pequeñas, los partidos ganan pocos escaños y suelen colocar en las primeras posiciones de las listas a hombres, por tanto, las posibilidades de que las mujeres salgan electas se reducen. Efecto, por cierto, que se acentúa cuando la fragmentación partidaria aumenta. En segundo lugar, porque las listas abiertas y

1. Las medidas que acompañaron a los sistemas de cuotas eran: $a$ ) crear una conciencia: utilizar a los medios de comunicación para centrar la atención pública en la importancia de una participación equilibrada entre hombres y mujeres; $b$ ) trabajar en alianza con los varones: esto comprende el diseño de programas, ya sea dentro o fuera de los foros políticos particulares, para que tomen en cuenta los intereses y se solidaricen con las mujeres involucradas en la política; $c$ ) ampliar la fuente de las mujeres aspirantes elegibles: esto significa fortalecer el interés de ellas para que participen en política; $d$ ) aplicar acciones positivas: el uso de cuotas; $e$ ) elevar los niveles generales de vida y el acceso a los recursos para las mujeres; $f$ ) incorporar los temas de género al debate general; $g$ ) fomentar la conciliación de la vida familiar y profesional; $\mathrm{y} h$ ) incrementar los niveles educativos. 
desbloqueadas dejan en manos del votante la conciencia de género. Además, en una competencia entre candidatos, las grandes perjudicadas siempre resultarán ser las mujeres, debido a su histórica invisibilidad en política, ya que son menos conocidas y disponen de menos recursos y apoyos del partido, hecho que retroalimenta y perpetúa la desventaja de éstas con relación a sus compañeros varones (Bou, 2003: 4). Por otra parte, es cierto que la eficacia de las listas cerradas y bloqueadas depende en gran medida de la propia disposición de la cúpula dirigente de los partidos, pero, al menos, garantizan un cupo mínimo.

Otro motivo es la propia elección del modelo de acción positiva. Algunos, como Bou (2003: 3), consideran que para que las leyes de cuotas incidan positivamente en pro de la representación femenina en el poder legislativo, éstas deben ser obligatorias, y no sólo exhortatorias o recomendatorias. De ahí que no puedan ser una simple declaración de intenciones en la que se estipule un porcentaje que se considere deseable y en la que los partidos políticos (especialmente sus máximos dirigentes) decidan sobre su conveniencia de implementarla (Bou, 2003: 4). La cuota debe ser imperativa, exigible y contemplar claras consecuencias jurídicas ante el incumplimiento de sus disposiciones (Bou, 2003: 4), aunque, en honor a la verdad, hay que decir que este tipo de sanciones no siempre tienen un efecto positivo a la hora de incrementar la representación femenina en los parlamentos nacionales.

Otro factor es el grado en el que se involucran las partes. En primer lugar, los partidos políticos son un actor crucial a la hora de facilitar el acceso de las mujeres al sistema político en proporciones igualitarias (Baer, 1993; Caul, 1999; Kohn, 1980). Téngase en cuenta que son los dirigentes de los partidos los que elaboran las candidaturas y, por tanto, son los que deciden los puestos en los que van a concurrir cada uno de los candidatos, y son ellos los que pueden establecer algún tipo de porcentaje para garantizar la paridad de sus listas. Pero ni siquiera este tipo de medidas pueden llegar a asegurar su éxito, ya que se puede cumplir con el requisito mínimo de mujeres en una lista, pero situándolas en posiciones donde no existen opciones reales de salir elegidas. Así ha sucedido en España, donde, pese a la reciente Ley de Igualdad de Género, ha perdido cinco puestos en el ranking de representación femenina. En segundo lugar, la voluntad de las autoridades en hacer cumplir las medidas establecidas imponiendo requisitos de ubicación o sanciones. Por ejemplo, este es el caso de Argentina, que, en su Ley de Cupos de 1991, fijó una cuota mínima de un $30 \%$ para que las mujeres fueran situadas en lugares donde hubiera ciertas posibilidades de ser elegidas. El resultado fue un éxito rotundo, ya que el porcentaje de mujeres con representación en el Parlamento aumento en 26,3 puntos después de fijarse tal medida. Pero no siempre es así, por ejemplo, Francia, pese a haber introducido una cuota del $50 \%$, presenta un balance negativo y ocupa el puesto 65 del ranking de representación de mujeres en los parlamentos nacionales. Y, en tercer lugar, habría que mencionar la propia voluntad de presionar que tienen los grupos organizados de mujeres, tanto dentro de los partidos políticos como en las organizaciones no gubernamentales (ONG). Tal ha sido así que, por ejemplo, el éxito que las mujeres han cosechado en los 
parlamentos escandinavos se debe, en buena medida, a la presión que ha ejercido este tipo de grupos femeninos a la hora de reclamar la instauración de un sistema de cuotas en la selección interna de sus candidatos.

Las condiciones socioculturales imperantes en los distintos países también han sido una variable determinante para incrementar la representación femenina. No nos cabe duda que la mejora en la esperanza de vida, el incremento de la tasa de presencia de la mujer en el mercado laboral, la disminución de la fertilidad o el mayor número de mujeres con estudios medios y superiores inciden positivamente en este aspecto. Naturalmente, el impacto de una cuota no puede ser el mismo en un país donde las mujeres, por ejemplo, tienen un elevado número de hijos que en uno que no, o en aquellos donde las mujeres ya se han incorporado al mercado laboral y poseen unos altos niveles de estudios que en los que las mujeres todavía se encuentran relegadas a labores caseras. De ahí que ese sea uno de los motivos, entre otros muchos, por el cual las zonas del África Subsahariana, el Pacífico y los Estados árabes sean las que presenten unos porcentajes de representación femenina que se sitúan por debajo de la media mundial.

En todo caso, se podría decir que, en la actualidad, pueden distinguirse dos tipos de cuotas: por un lado, las cuotas constitucionales y legales y, por otro, las cuotas voluntarias. Las primeras son aquellas medidas que las constituciones o las leyes nacionales consideran de obligado cumplimiento por parte de los partidos en las elecciones nacionales o subnacionales y tienen aplicación en la propia candidatura presentada por los partidos políticos para las elecciones, o en la reserva de un determinado número de escaños en las asambleas parlamentarias. Las cuotas legislativas, generalmente, disponen que las mujeres formen entre un $25 \%$ y $50 \%$ de todos los candidatos. En la reserva de escaños, el esquema más común, sin embargo, es aquél en el que los escaños femeninos se distribuyen entre los partidos políticos en base a su proporción en el voto (Krook, 2005). Las segundas son las disposiciones que se incorporan a los estatutos partidarios a iniciativa de los propios partidos, y que supone que una determinada cantidad de puestos a cargos electivos o partidistas deben ser reservados a las mujeres. Dinámica ésta que funciona de manera similar en muchos partidos políticos. Por ejemplo, el Partido Social Demócrata de Alemania introdujo una cuota de un $25 \%$ en 1988 , la cual fue elevada a un $33 \%$ en 1994 y a un 44\% en 1998. Algo parecido ha sucedido en el Partido Socialista Obrero Español. Aunque, en ambos casos, para lograr que sean realmente efectivas, se están estableciendo medidas tales como la existencia de requisitos de ubicación y la imposición de sanciones en caso de incumplimiento. Los primeros tienen como objetivo impedir que los partidos políticos cumplan con el cupo confinando a las mujeres en los últimos lugares de las listas. Así, muchas leyes se están dedicando a especificar la cuota mínima que debe aplicarse a cada tercio de la lista. Las segundas suelen consistir en la denegación de parte de las autoridades electorales a inscribir las listas que no cumplan con los requisitos establecidos, aunque también se ha apostado por la sanción económica en caso de incumplimiento de las medidas. 
En España, fue IU la primera fuerza política en establecer un sistema de cuotas en su reglamentación interna. Luego sería el PSOE el que establecería distintas medidas para favorecer la incorporación de mujeres tanto en sus órganos de dirección como en los cargos de representación. Así, en 1988, fijó la cuota femenina del 25\%. En 1994, se garantizó que, cuando en un ámbito territorial la afiliación femenina fuese mayor al $25 \%$, la reserva de puestos sería cinco puntos superior a dicho porcentaje. En 1997, se dio un paso más y se exigió el cumplimiento del principio de democracia paritaria, basado en el criterio de que ningún grupo de sexo tuviese una presencia menor del $40 \%$ ni mayor del 60\%. En este mismo sentido, el 15 de marzo de 2007, el Parlamento español aprobó, por iniciativa del Gobierno socialista, una ley de igualdad con los votos a favor de todos los partidos del arco parlamentario y con la abstención del Partido Popular. Esta ley obliga a aquellas empresas que tengan más de 250 empleados a negociar con los agentes sociales los planes de igualdad. Disponen de un plazo de ocho años para que los consejos de administración tengan un $40 \%$ de mujeres. También se contempla en la misma la ampliación del permiso de maternidad para los casos de parto prematuro, se establece bonificaciones y escisiones de la Seguridad Social a trabajadoras autónomas, se busca la paridad, se intenta fijar medidas que fomenten la igualdad, etc. Aunque, pese a todo, todavía hay partidos como el PP que no se han decantado por ninguna medida de este tipo, pero eso no quiere decir que no hayan apostado por aumentar la presencia femenina en sus órganos de gobierno y de representación.

\section{Las mujeres en el Grupo Parlamentario Popular}

En España, el Partido Popular (PP) es el único de los tres partidos con representación nacional que no contempla estatutariamente una política de discriminación positiva a favor de la mujer, es decir, lo que en el PSOE e Izquierda Unida (IU) se ha denominado «sistema de cuotas». Pero no por ello los populares han renunciado a contar con mujeres en puestos de relevancia (Larrea, 1999). Es más, desde 1993, han incrementado su presencia, tanto en los puestos de responsabilidad del partido, como en las listas electorales, y lo que es más importante, se ha producido un cambio en la actitud que venían mostrando hacia ciertos temas relacionados con la política de género (Ruiz Jiménez, 2002: 337). Estas modificaciones han sido impuestas «desde arriba», con el objetivo de mejorar la percepción y la valoración del partido entre las mujeres (Ruiz Jiménez, 2002: 333). Por tanto, evidentemente, a pesar de no contar con un sistema de cuotas, las mujeres han obtenido un plus dentro del partido, como se pudo comprobar en el XIV Congreso Nacional (2002), donde cada ponencia fue elaborada y presentada por un hombre y una mujer. Ésta fue la fórmula que eligió la dirección nacional para dejar patente su apuesta por la integración femenina dentro de la vida política. Es más, incluso podríamos estar hablando de un sistema de cuotas encubierto. La idea es clara, el PP dice sí a la participación de la mujer, pero sin que sea necesario implantar ni cuotas ni normas que vayan dirigidas en ese sentido. En definitiva, de lo que se 
Tabla 1. Las mujeres del Grupo Parlamentario Popular (1986-2004)

\begin{tabular}{|c|c|c|c|c|c|c|c|c|c|c|c|c|c|}
\hline & \multicolumn{2}{|c|}{1986} & \multicolumn{2}{|c|}{1989} & \multicolumn{2}{|c|}{1993} & \multicolumn{2}{|c|}{1996} & \multicolumn{2}{|c|}{2000} & \multicolumn{2}{|c|}{2004} & 2008 \\
\hline & Frec. & $\%$ & Frec. & $\%$ & Frec. & $\%$ & Frec. & $\%$ & Frec. & $\%$ & Frec. & $\%$ & Frec. $\%$ \\
\hline Diputadas & 11 & 10,3 & 11 & 9 & 24 & 14,5 & 33 & 17,6 & 68 & 29,7 & 45 & 29,4 & 4730,51 \\
\hline Diputados & 96 & 89,7 & 111 & 91 & 142 & 85,5 & 154 & 82,4 & 161 & 70,3 & 108 & 70,6 & 11069,49 \\
\hline Total & 107 & 100 & 122 & 100 & 166 & 100 & 187 & 100 & 229 & 100 & 153 & 100 & $154 \quad 100$ \\
\hline
\end{tabular}

Fuente: elaboración propia.

trata es de transmitir al electorado femenino que la incorporación de las mujeres en el partido va más allá de una mera campaña de marketing destinada a recabar el mayor número de votos posible.

Es decir, el PP no ha establecido "cuota» alguna, pero habría que saber cuál ha sido el impacto que ha obtenido esta estrategia en el Congreso de los Diputados. En este sentido, habría que decir que, según datos aportados por la tabla 1 , la inclusión de mujeres no sólo ha sido escasa, sino que se ha mantenido prácticamente estancada hasta la quinta legislatura (1993-1996). La llegada de José María Aznar a la presidencia del partido ha venido a modificar esta situación y, desde entonces, la dirección nacional del partido ha sido consciente de que estaba perdiendo progresivamente el apoyo del electorado femenino. De ahí que comience a desarrollar una estrategia que se dirija fundamentalmente hacia dos vertientes:

1) Aumentar el número de mujeres, tanto en los órganos internos del partido, como en aquellos en los que ostenta representación.

2) Cambiar su discurso y, por tanto, su posicionamiento en los temas que afectan a las políticas de género.

Respecto a lo primero, como podemos observar en la tabla 1, las pautas marcadas desde la ejecutiva tienen su repercusión en el Grupo Parlamentario y alcanzan su pico más álgido en la novena legislatura (2008-2012), que es cuando las mujeres ocupan el 30,51\% de los escaños. De todos modos, estas cifras todavía se encuentran lejos de una política paritaria o de las cifras que presenta el partido socialista, ya que, en las dos últimas legislaturas, las mujeres socialistas han representado el 46,30 y el 43,20\%, respectivamente. Y más cuando las cifras de los hombres en el Grupo Parlamentario Popular nunca han bajado del $70 \%$ e incluso han llegado a alcanzar una representación del 90\%.

No obstante, como decimos, tanto en uno como en otro partido, la presencia femenina en las Cortes Generales sólo empieza a tener cierta relevancia a partir de 1989, aunque todavía se encuentra alejada de los postulados de democracia paritaria que han sido, por ejemplo, defendidos por los socialistas, como queda patente en la tabla 2. Sólo en la octava y la novena legislaturas los socialistas han logrado sobrepasar la barrera del $40 \%$., aunque hay que advertir que, pese a la Ley de Igualdad, las mujeres han visto disminuida su presencia en tres décimas en la presente legislatura respecto a la anterior. Los pobres resultados que arroja la representación femenina en el Partido Socialista 
Tabla 2. Porcentaje de las mujeres del PSOE y del PP en las Cortes Generales

\begin{tabular}{lcccccccccc}
\hline PSOE & $1977-79$ & $1979-82$ & $1982-86$ & $1986-89$ & $1989-93$ & $1993-96$ & $1996-2000$ & $2000-04$ & $2004-08$ & $2008-\ldots$ \\
\hline $\begin{array}{l}\text { Mujeres } \\
\%\end{array}$ & - & - & 14 & 13 & 30 & 28 & 39 & 46 & - & - \\
\hline PP & $1977-79$ & $1979-82$ & $1982-86$ & $1986-89$ & $1989-93$ & $1993-96$ & $1996-2000$ & $2000-04$ & $2004-08$ & $2008-\ldots$ \\
\hline Mujeres & & & 1 & 5 & 11 & 21 & 22 & 46 & 42 & - \\
$\%$ & 6 & 11 & 0,9 & 5,9 & 10,3 & 14,8 & 14,2 & 25,1 & 28,3 & 29,87 \\
\hline
\end{tabular}

Fuente: Instituto de la Mujer.

pueden obedecer a que la cuota del $25 \%$, primero, y la del $40 \%$, después, se ha aplicado a lo largo y ancho de toda la lista, por lo tanto, son muy pocas las mujeres que se sitúan en los puestos de salida, así, difícilmente pueden obtener un escaño en la carrera de San Jerónimo. Por ello, los socialistas se han visto ante la obligación de inclinarse en la mayoría de las circunscripciones por lo que se ha denominado "la cremallera», es decir, hombre-mujer-hombre-mujer (Cernuda, 2000: 155), para dar cumplimiento a las disposiciones estatutarias. Disposición reglamentaria que, por otra parte, como ya hemos mencionado, sólo se ha cumplido a partir de la octava legislatura (2004-...), donde las mujeres se sitúan en el $46,30 \%$ y los hombres, en el 53,7\%. Por tanto, se podría decir que la ejecutiva socialista ha sido bastante flexible a la hora de aplicar las medidas reglamentarias que ella misma ha elaborado y aprobado.

Respecto al PP, podríamos decir que parece haberse dado cuenta del cambio que se está produciendo en la preferencia partidista de las mujeres, y que ésta está favoreciendo a los socialistas. El hecho de que el partido no sea capaz de llegar a este sector de la población, se considera, en términos generales, un gran problema. De ahí que el objetivo que se marque el partido sea mejorar la percepción y la valoración del electorado femenino respecto a su organización (Ruiz Jiménez, 2002: 333), sin por ello caer en el sistema de cuotas como en el partido socialista. Por tanto, no es de extrañar que la representación femenina haya experimentado un enorme crecimiento, si tenemos en consideración que, entre 1982 y 2004, según nos indica la tabla 2, las mujeres han incrementado su presencia en 29 puntos. La razón podemos encontrarla en los excelentes resultados que el partido cosecha a partir de 1996 y a la estrategia que viene impulsando la cúpula nacional desde que Aznar se hizo con las riendas del partido. El problema está en que si estas cifras las comparásemos con las que arrojan las mujeres socialistas, el crecimiento sufrido por las mujeres populares se vería medio ensombrecido, al situarse 11,33 puntos por debajo en el Congreso. Por tanto, según los datos que nos ha proporcionado esta tabla, podemos concluir que, a priori, los sistemas de cuotas han resultado ser más efectivos para garantizar la inclusión de las mujeres en la Cámara Baja, dada cuenta que el partido que se ha decantado por ellas, el socialista, cuenta con un mayor número de mujeres en su grupo parlamentario que los que no lo han hecho, los populares. En todo caso, viendo la representación que las mujeres de ambos partidos tienen en las Cortes Generales, cabe advertir que la Ley de 
Igualdad apenas ha tenido repercusión. Si miramos los datos, podríamos llegar a afirmar que no se ha producido ningún avance, incluso, es más, en el caso del PSOE, se podría hablar de un ligero retroceso. Todo porque, con ley o sin ella, el primer puesto de la lista sigue estando reservado, mayoritariamente, a los hombres, ya que, en las últimas elecciones generales, más del $70 \%$ de las cabezas de listas de ambos partidos eran candidatos, mientras que las mujeres han quedado relegadas, en el mejor de los casos, al segundo puesto, ya que en muchos otros ni si quieran han llegado a ocupar ni el primer ni el segundo puesto, y la ley se extiende a lo largo de toda la candidatura.

En cuanto al segundo tema, el PP ha ido transformando progresivamente su discurso sobre aquellas cuestiones que están directamente relacionadas con la política de género o que afectan a las mujeres. Así, el PP ha pasado de alinearse en contra del aborto a aceptar la despenalización de la interrupción voluntaria del embarazo, a admitir que a las parejas de hecho se les reconozcan sus derechos, a apostar por la igualdad de género, a no oponerse al divorcio, a impulsar medidas que contribuyan a la contratación indefinida de mujeres en campos donde estén poco representadas, a promover incentivos fiscales para que los empresarios contraten a mujeres, a crear programas especiales para su reincorporación al mercado de trabajo, a fomentar medidas a favor de la familia, etc. (Sánchez, 2003). Hay que tener en cuenta que estos temas son altamente novedosos para un partido como Alianza Popular (AP), que mantenía una actitud muy conservadora para los asuntos relacionados con la familia y la sexualidad.

\section{a) Edad}

Teniendo en cuenta todo esto, habría que analizar el perfil que presentan las nuevas mujeres del Partido Popular para saber hasta qué punto siguen los patrones marcados por su formación. No hay duda que se ha apostado por un tipo de mujer muy determinado: joven, licenciada, sin importar la experiencia de la que gocen y, a ser posible, con padrinos dentro del partido (Cernuda, 2000: 31). Así, si nos fijamos en la edad de las diputadas del Grupo Parlamentario Popular, podremos observar que el colectivo mayoritario en el que están situadas, con la única excepción de la sexta legislatura (1996-2000), es el que se sitúa entre los 35 y los 44 años. Si a esto le sumamos los índices nada despreciables que presentan las mujeres que tienen entre 25 y 34 años, podremos concluir que éstas poseen una media de edad mucho baja que la de sus compañeros del Grupo Parlamentario (ver tabla 3), los cuales, por el contrario, mantienen una media de edad que comprende entre 45 y 54 años, aunque su preponderancia es evidente a partir de la sexta legislatura (1996-2000), porque hasta entonces los diputados de 35 a 44 años mantenían unas cifras muy parejas a los primeros (Sánchez, 2007b).

En todo caso, desde la llegada de Aznar a la presidencia del partido, el grupo ha visto como se ha ido renovando con una serie de diputados procedentes de la misma generación que la de su máximo dirigente, lo que significa que el grupo parlamentario se ha rejuvenecido, aunque seguramente en un menor 

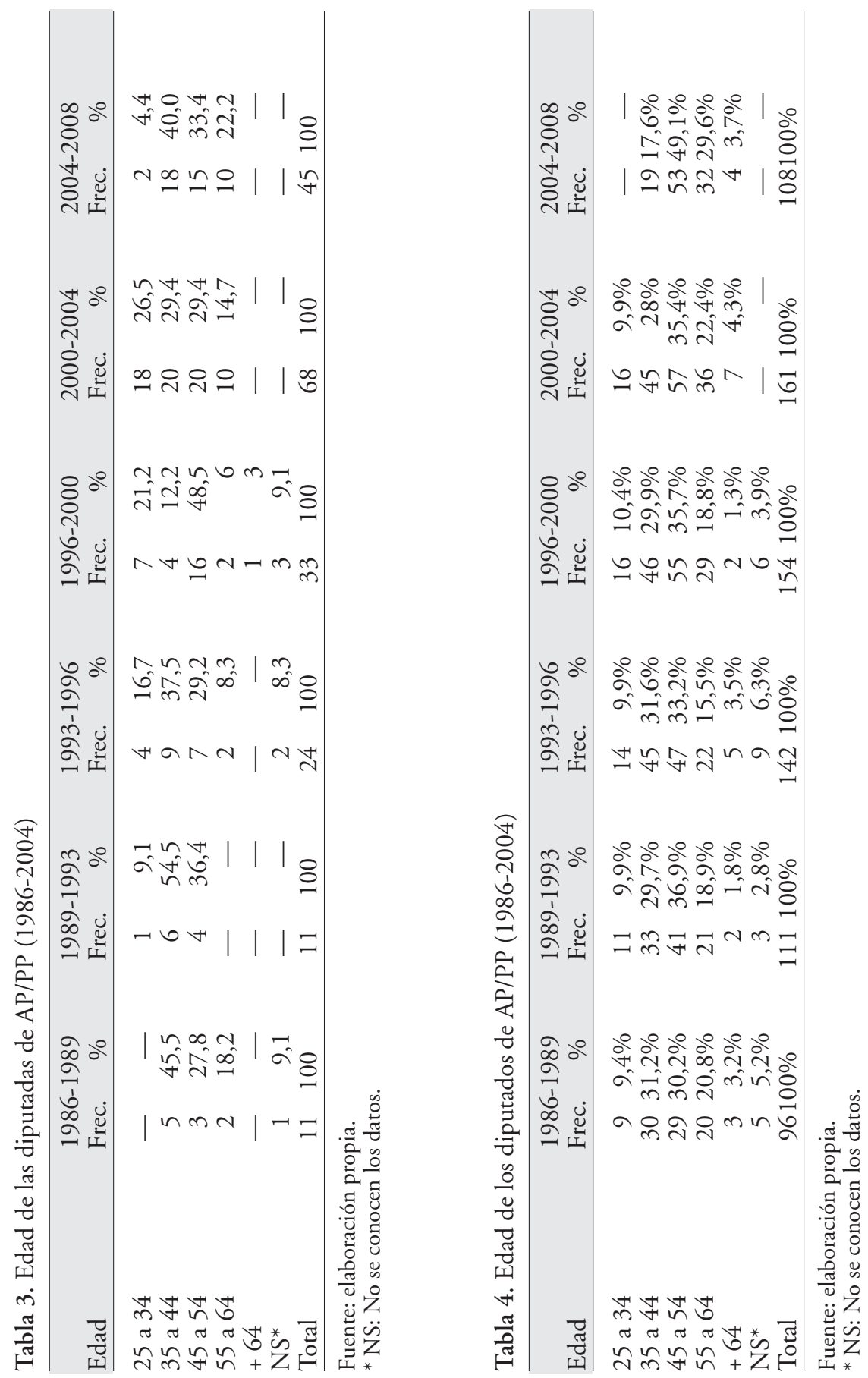
grado de lo que, en un principio, se podría presuponer. $Y$ es que, a medida que se ha ido reduciendo el grupo de edad entre 35 y 44 años, se ha ido incrementado los restantes superiores. Así, por ejemplo, en 1996, los diputados que contaban entre 55 y 64 años aumentaron sus porcentajes en tres puntos, en el 2000 fueron casi cuatro, y en el 2004, siete, es decir, en total, catorce puntos, ya que se ha pasado de un 15,5\% (1993) a un 29,6\% (2004). Esto quiere decir que la renovación viene marcada por dos generaciones que se encuentran parejas. Cuando José María Aznar encabeza por primera vez las listas del Partido Popular en 1989 cuenta con 36 años, sin embargo, el grupo de edad más numeroso es el de 45 y 54 años. En la siguiente legislatura, se produce un equilibrio entre los diputados que tienen entre 35 y 45 años y los que tienen entre 45 y 54, lo que nos indica que el presidente del partido no sólo se ha rodeado de hombres de su misma generación, que por aquel entonces serían los de 35 a 45 años, sino que, además, lo hace de otros procedentes justo de una superior. Por tanto, la mayor renovación y, por consiguiente, la ruptura con el pasado se produce precisamente en la quinta legislatura (1993-1996).

Por lo tanto, sin lugar a dudas, sí hay una renovación en el Grupo Parlamentario desde la llegada de Aznar a la presidencia del partido. Es más, si hubiéramos tenido como objeto de estudio todas las legislaturas, podríamos haber visto que, en 1977, el PSOE era el grupo parlamentario más joven en el Congreso de los Diputados y el que por aquél entonces representaba Alianza Popular, el más viejo. Esta situación cambia y se invierte, como venimos diciendo, a partir de 1989, lo que significa que el Grupo Popular ha sabido renovarse, pero desde entonces ha comenzado un proceso de madurez que suele estar unido con la consolidación electoral de los partidos y, por tanto, de la elite dominante.

Lo que viene a corroborar nuestra hipótesis de partida de que la incorporación de las mujeres al Grupo Parlamentario Popular responde principalmente a una decisión de la cúpula nacional. Ya que si la práctica habitual del PP hubiera sido integrar a las mujeres dentro de los órganos de representación institucional, aunque hubiese sido en un número reducido, tendría que haber cierta representación de ellas en alguno de los grupos de edad que comprenden

Tabla 5. Edad de las diputadas del PSOE (1986-2004)

\begin{tabular}{|c|c|c|c|c|c|c|c|c|c|c|c|c|}
\hline \multirow[b]{2}{*}{ Edad } & \multicolumn{2}{|c|}{ 1986-1989 } & \multicolumn{2}{|c|}{$1989-1993$} & \multicolumn{2}{|c|}{ 1993-1996 } & \multicolumn{2}{|c|}{$1996-2000$} & \multicolumn{2}{|c|}{$2000-2004$} & \multicolumn{2}{|c|}{ 2004-2008 } \\
\hline & Frec. & $\%$ & Frec. & $\%$ & Frec. & $\%$ & Frec. & $\%$ & Frec. & $\%$ & Frec. & $\%$ \\
\hline 25 a 34 & & & & & & & 1 & & 4 & & 17 & \\
\hline 35 a 44 & 1 & & 1 & & 2 & & 5 & & 16 & & 14 & \\
\hline 45 a 54 & & & 2 & & 4 & & 13 & & 24 & & 40 & \\
\hline 55 a 64 & & & & & & & & & 6 & & 12 & \\
\hline+64 & & & & & & & & & 1 & & 0 & \\
\hline NS* & 28 & & 31 & & 29 & & 33 & & 0 & & 1 & \\
\hline Total & 19 & & 34 & & 35 & & 52 & & 51 & & 84 & \\
\hline
\end{tabular}

Fuente: elaboración propia.

* NS: No se conocen los datos. 
entre los 55 y 64 años y más de 65, como sucede con sus compañeros del grupo parlamentario, cosa que, evidentemente, apenas sucede, como nos demuestra la tabla 3. De ahí que las mujeres del PP sean de la misma generación que la de su presidente o de una anterior, como consecuencia de la renovación que se lleva a cabo en el partido desde 1989 y de la necesidad imperante de incorporarlas al mundo de la política activa.

Respecto al PSOE, habría que mencionar que el grupo de edad más numeroso, a diferencia de las populares, es el de 45 a 54 años, lo que nos indica una pauta de comportamiento distinta. Los dos partidos han apostado por ir integrando mujeres en sus respectivos grupos parlamentarios, pero mientras que el PSOE lo ha hecho a través de un sistema de cuota estatutario, por lo cual se pone menos énfasis en las características de la mujer, el PP busca un determinado modelo de mujer como una manera de llamar la atención del electorado, lo que implica, a su vez, que practica una estrategia determinada y deliberada para incorporar a mujeres a la arena política. En todo caso, según los datos de la tabla 5, pese a ser escasos dada la poca información existente en el anuario del Congreso de los Diputados, cabe mencionar que apenas existen mujeres entre los grupos de mayor edad, lo que nos viene a decir que, en el Grupo Socialista, ha existido un gran relevo de la elite femenina del partido, ya que, si no, lo normal hubiera sido que los números en esa horquilla de edad fuera más elevada, sobre todo a partir de la octava y la novena legislaturas. Lo mismo sucede en el PP, por lo cual vemos que ambos partidos han seguido, pese a todo, la misma estrategia.

\section{b) Nivel educativo}

En cuanto al nivel de estudios que poseen, podemos ver que más del 65\% ha obtenido un título universitario. Predominan las licenciadas sobre las diplomadas y las doctoradas (ver tabla 6). Por tanto, en general, se cumple a la perfección con la premisa que parece definir a las mujeres del PP como jóvenes y licenciadas. Porque si no hubiera una política de integración de mujeres, seguramente el nivel educativo de éstas sería más bajo, dado que formarían parte de él las mujeres de una generación posterior que, en España, en la mayor parte de los casos, sólo contaban con estudios preuniversitarios. En cualquier caso, pese a que, como podemos comprobar, el nivel educativo de las parlamentarias del Grupo Popular es elevado, más si lo comparamos con la media de la población española, son los porcentajes que cabría esperar para una elite que se presupone debe estar altamente cualificada para poder desempeñar las funciones que le deben ser encomendadas como consecuencia de su trabajo dentro de la Cámara ${ }^{2}$.

2. El Instituto Nacional de Estadística nos indica que el nivel educativo de los ciudadanos españoles, con datos de 2001, es el siguiente: analfabetos (3,3\%), sin estudios (12,3\%), educación primaria $(25,9 \%)$, educación secundaria $(40,1 \%)$, educación superior $(18,5 \%)$, educación universitaria incluidos primer, segundo y tercer ciclos (12,9\%) (datos de los indicadores sociales, edición 2003. INE). 
Tabla 6. Nivel de estudios de las diputadas de AP/PP (1986-2004)

\begin{tabular}{|c|c|c|c|c|c|c|c|c|c|c|c|c|}
\hline \multirow[b]{2}{*}{ Estudios } & \multicolumn{2}{|c|}{ 1986-1989 } & \multicolumn{2}{|c|}{$1989-1993$} & \multicolumn{2}{|c|}{ 1993-1996 } & \multicolumn{2}{|c|}{$1996-2000$} & \multicolumn{2}{|c|}{$2000-2004$} & \multicolumn{2}{|c|}{ 2004-2008 } \\
\hline & Frec. & $\%$ & Frec. & $\%$ & Frec. & $\%$ & Frec. & $\%$ & Frec. & $\%$ & Frec. & $\%$ \\
\hline Primaria & - & - & - & - & - & - & - & - & 3 & 4,4 & - & - \\
\hline Bachiller & 3 & 27,3 & 1 & 9,1 & 3 & 12,5 & 6 & 18,2 & 8 & 11,8 & 4 & 8,9 \\
\hline Diplomado & 1 & 9,1 & 2 & 18,2 & 4 & 16,7 & 3 & 9,1 & 2 & 2,9 & 3 & 6,7 \\
\hline Licenciado & 4 & 36,4 & 5 & 45,5 & 11 & 45,8 & 17 & 51,5 & 40 & 58,8 & 29 & 64 \\
\hline Doctorado & 3 & 27,3 & 3 & 27,3 & 4 & 16,7 & 4 & 12,1 & 8 & 11,8 & 3 & 6,7 \\
\hline Máster & - & - & - & - & - & - & 1 & 3 & 5 & 7,4 & 5 & 11,1 \\
\hline NS* & - & - & - & - & 2 & 8,3 & 2 & 6,1 & 2 & 2,9 & 1 & 2,2 \\
\hline Total & 111 & 100 & 111 & 00 & 24 & 100 & 331 & 100 & 68 & 100 & 45 & 100 \\
\hline
\end{tabular}

Fuente: elaboración propia.

* NS: No se conocen los datos.

Tabla 7. Nivel de estudios de las diputadas del PSOE (1986-2004)

\begin{tabular}{|c|c|c|c|c|c|c|c|c|c|c|c|c|}
\hline \multirow[b]{2}{*}{ Estudios } & \multicolumn{2}{|c|}{ 1986-1989 } & \multicolumn{2}{|c|}{$1989-1993$} & \multicolumn{2}{|c|}{ 1993-1996 } & \multicolumn{2}{|c|}{$1996-2000$} & \multicolumn{2}{|c|}{$2000-2004$} & \multicolumn{2}{|c|}{ 2004-2008 } \\
\hline & Frec. & $\%$ & Frec. & $\%$ & Frec. & $\%$ & Frec. & $\%$ & Frec. & $\%$ & Frec. & $\%$ \\
\hline Primaria & & & & & & & & & 2 & & & \\
\hline Bachiller & 1 & & 2 & & 1 & & 8 & & 6 & & 6 & \\
\hline Diplomado & 7 & & 6 & & 8 & & 8 & & 12 & & 15 & \\
\hline Licenciado & 10 & & 21 & & 21 & & 25 & & 21 & & 44 & \\
\hline Doctorado & 1 & & & & 3 & & 3 & & 6 & & 10 & \\
\hline Máster & & & 1 & & & & & & & & 5 & \\
\hline NS* & 1 & & 5 & & 2 & & 7 & & 4 & & 4 & \\
\hline Total & 19 & & 35 & & 35 & & 51 & & 51 & & 4 & \\
\hline
\end{tabular}

Fuente: elaboración propia.

* NS: No se conocen los datos.

Las mujeres socialistas tampoco presentan grandes diferencias respecto a las populares. Según los datos que nos aporta la tabla 7 , el grupo mayoritario está formado por el de las licenciadas y el de las diplomadas. Pero, de nuevo, como en el caso anterior, se ve claramente que la inclusión de las mujeres responde a una estrategia claramente programada, como demuestra el hecho de tener un elevado grado renovación de la elite femenina parlamentaria, y la inclusión cada vez mayor de mujeres con un nivel más elevado de estudios. Por tanto, en este caso, la política de cuotas del PSOE y la política de integración del PP parece seguir las mismas pautas.

\section{c) Ocupación}

En cuanto a su experiencia profesional, habría que decir que provienen mayoritariamente de la Administración y de la educación, aunque, a partir de la sexta legislatura (1996-2000), se han ido incorporando cada vez con más fuerza las abogadas, cuyo grupo ha pasado del 0\% de 1986 al 19,1\% de 2000. Esto no es de extrañar cuando el $50 \%$ de los diputados son licenciados en 
Derecho, lo que indudablemente también tiene su repercusión en el hecho de que una buena parte de ellas hayan optado por la carrera funcionarial. Con ello, no queremos decir que éstos sean los únicos que opositen a los distintos cuerpos de la Administración, pero sí que lo hacen en mayor medida que los procedentes de otras licenciaturas. No obstante, que la mayoría de los diputados sean funcionarios implica, por un lado, que los parlamentarios tienen garantizada su carrera profesional con independencia de su actividad política y, por otro, que pueden actuar de una manera más autónoma. La abundancia de los funcionarios públicos entre las elites parlamentarias no debe extrañar, para empezar, porque los funcionarios tienen una mayor proximidad a la gestión pública que los miembros de las profesiones restantes y, para continuar, porque la vocación o el interés por el servicio público es un rasgo que se supone a funcionarios y políticos en mayor medida que a individuos dedicados a otras profesiones (García-Guereta, 2001: 465-466).

Por otra parte, los docentes son el segundo grupo en importancia. La continua implicación de los docentes, sobre todo los universitarios, en movimientos y grupos relacionados con el ámbito político, pueden a llegar a explicar este hecho. No obstante, el grupo de abogadas es el que ha experimentado un mayor crecimiento, tal vez porque se presupone que están más familiarizadas con la actividad que se desarrolla en el Parlamento que si tuvieran cualquier otra profesión. Además, su retorno a la vida profesional suele ser menos dificultosa que cualquier otra, con la excepción, claro está, de los funcionarios. Además, es curioso comprobar que, pese a que nuestras sociedades están impregnadas por el aroma de las políticas de género, sigue siendo muy reducido el número de mujeres que desempeñan puestos que son considerados «masculinos» por antonomasia, como pueden ser los ejecutivos, ingenieros, médicos y empresarios. Sólo hay que ver que, durante la quinta (1993-1996) y la sexta legislaturas (1996-2000), el Grupo Parlamentario Popular no cuenta con ninguna mujer que ejerza esas profesiones. Es cierto, también, que este tipo de carreras profesionales no suelen abundar en el mundo político, porque normalmente éste suele ofrecer pocos incentivos para unos profesionales que están mejor pagados y obtienen un mayor reconocimiento fuera que dentro de ella. En definitiva, las mujeres del Grupo Popular proceden principalmente de dos campos, el funcionarial y el docente.

En cuanto a las diputadas socialistas, cabe decir que proceden principalmente de la función pública y la docencia. El motivo obedece a las mismas causas que en el caso del PP. Sin embargo, según la tabla 9, entre las mujeres socialistas, a diferencia de las populares, hay un número mayor de cargos directivos, médicos e ingenieras, sobre todo en la última legislatura. No obstante, en ambos casos, estas cifras nos indican que el porcentaje de profesionales procedentes del ámbito privado es muy inferior al del sector público. Por ejemplo, tomando el cómputo global de los datos de ambos grupos parlamentarios, las empresarias han pasado de no estar presentes en la tercera legislatura (19861989) a representar un 4,4\% en la octava. Los cargos directivos siguen más o menos esta misma línea de crecimiento: en 1986, representaban el 9,1\%, mien- 

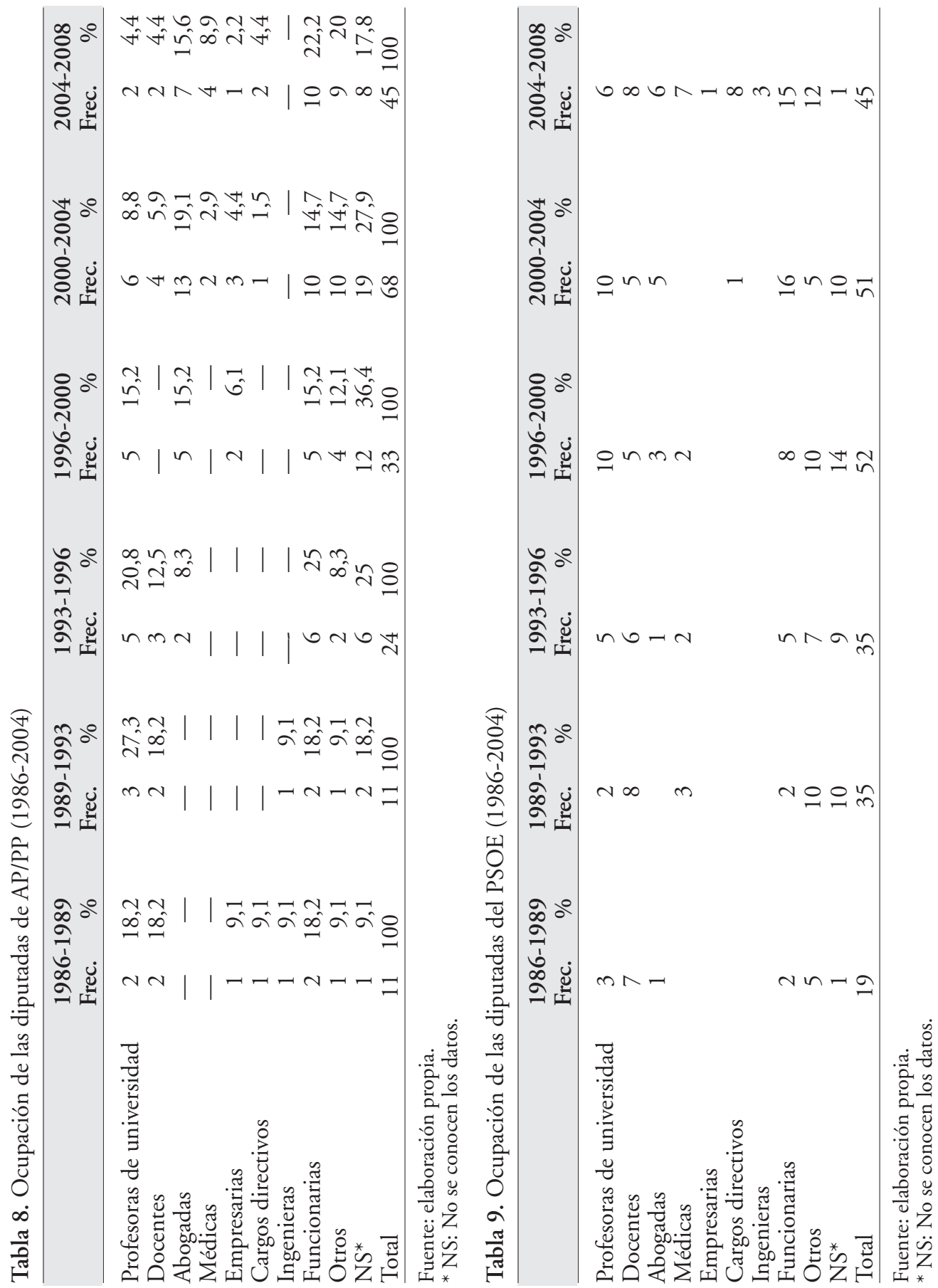
tras que, en la octava legislatura, sólo alcanzaban el 13,2\%. El poco atractivo que presenta la actividad política para unos profesionales que obtienen mayor reconocimiento y retribución en sus respectivos campos puede ser la causa de la escasa aceptación que tiene la actividad pública en este tipo de ámbitos. Además, las mujeres populares siguen prácticamente el mismo patrón que el diseñado por las socialistas, lo cual indica de nuevo que la política de integración de mujeres es una labor instrumentada desde la cúpula nacional. Además, en algunos de los casos, el simple hecho de estar alejada de su actividad profesional durante el periodo que abarca una legislatura puede dificultar su reinserción en el mercado laboral, puesto que las diputadas que dejan su escaño tienen añadida una connotación especial: no pueden desarrollar ninguna actividad que implique valerse de la información privilegiada que han obtenido durante su estancia en la Cámara. Esto ha llevado a que los diputados españoles en general sean menos profesionales que los del resto de Europa. Ello es debido a varios motivos: 1) por la escasa relación que tiene el Parlamento con los grupos de interés organizados; 2) porque, desde 1983, es imposible compaginar el escaño en la Cámara con su trabajo fuera de ella; 3) por el fuerte control partidista y la jerarquización de la actividad parlamentaria, y 4) por la poca relevancia que tiene el quehacer del Parlamento (López, 1997).

\section{d) Experiencia en cargos del partido y públicos}

Por otra parte, anteriormente, cuando estábamos definiendo los rasgos característicos de las mujeres del PP, decíamos que no se tenía en cuenta a la hora de ser incluidas en las listas electorales del partido la experiencia que poseían para desempeñar un cargo público. Y es precisamente eso lo que vamos a analizar ahora. Por ello, para estudiar el grado de profesionalidad política de las diputadas, habrá que fijarse en cuál ha sido su experiencia dentro de los órganos del partido y en los cargos de representación institucional. Hay que indicar que estas cuatro últimas tablas se han realizado tomando como referencia el cargo más elevado que ha ejercido cada diputada en cada una de las legislaturas correspondientes. La JDN y CEF son los únicos órganos que no han sido considerados para el análisis, dado que toda diputada nacional, por el hecho de serlo, es miembro nato de ella, por lo que su inclusión distorsionaría completamente los resultados del estudio, ya que, en función de ello, todas las parlamentarias nacionales acumularían experiencia a nivel nacional. También han sido contabilizadas las diputadas que se han ido incorporando procedentes de otras fuerzas políticas, en base a los puestos que ocupaban en sus partidos antes de su inclusión en sus grupos respectivos dentro del Congreso de los Diputados.

En primer lugar, según la tabla 10, habría que decir que la experiencia que tienen las mujeres populares en los órganos del partido se centra primordialmente en el ámbito nacional y regional. Desde la sexta legislatura (1996-2000), prima este último. No obstante, en un principio, parece que existe un aparente equilibrio entre ambos grupos que se mantiene durante dos legislaturas consecutivas, pero éste se rompe en la quinta (1993-1996), cuando las diputadas 


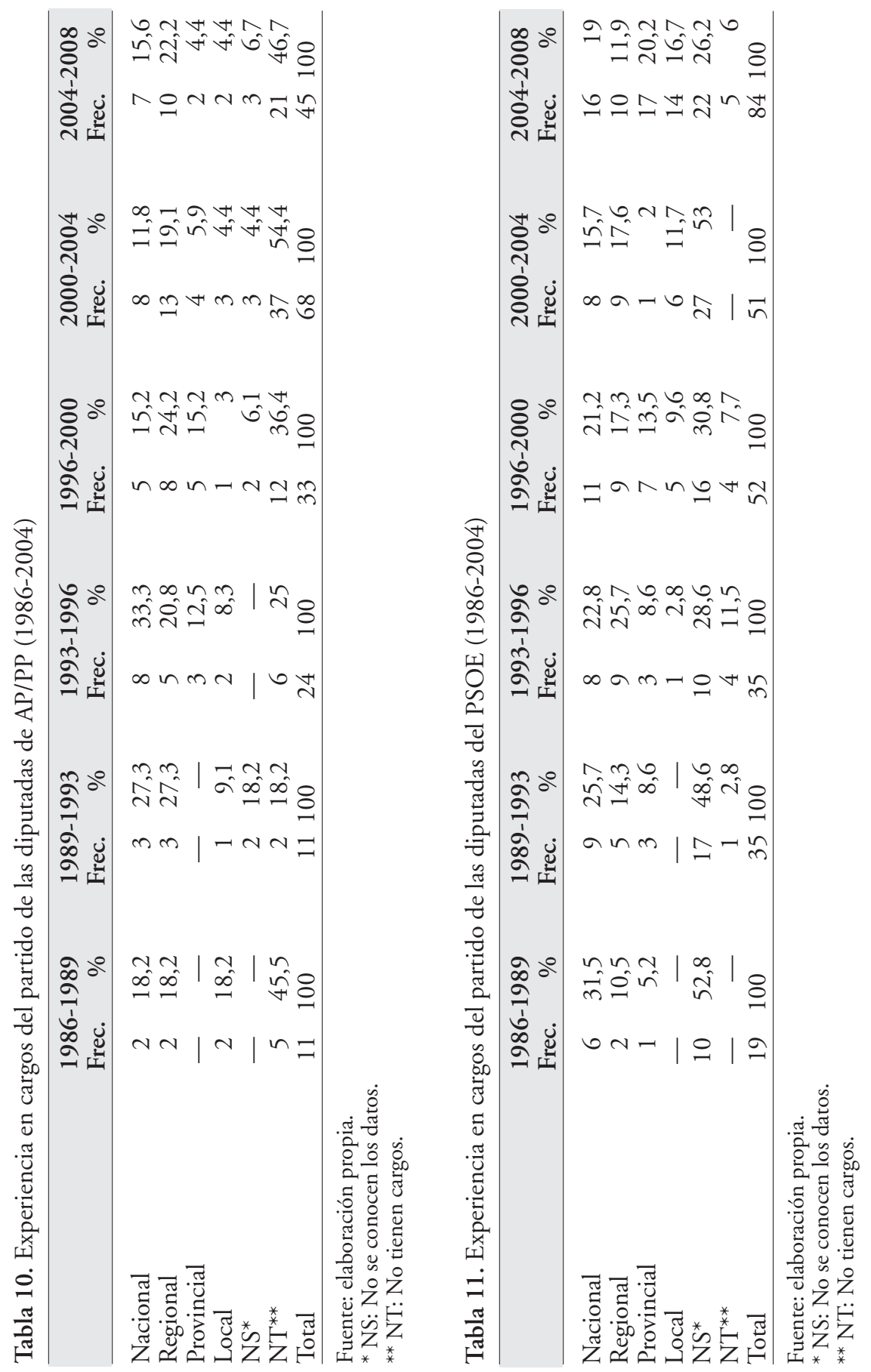


con cargos nacionales lograron superar a las del nivel regional. Después siempre ha habido un predominio de las segundas respecto a las primeras. Que esto suceda así viene a demostrar, una vez más, que la incorporación de las mujeres en el grupo parlamentario y en los órganos de dirección del partido obedece a una operación orquestada directamente por su cúpula dirigente. Hay que tener en cuenta tres hechos: 1) la política de inclusión se centra principalmente en el ámbito local y regional, lo que las habilita para que ocupen puestos en las ejecutivas territoriales; 2) los resultados que obtienen las mujeres en los ayuntamientos en los que se presentan les permiten adquirir unos poderes que les catapulten a los órganos de dirección regionales, sin embargo, pese a este éxito en el ámbito municipal, apenas hay mujeres que posean experiencia en el partido en el ámbito local, cuando es el ámbito institucional donde han adquirido mayor protagonismo. La explicación es sencilla, y corrobora nuestra hipótesis, las mujeres populares que normalmente han desempeñado funciones públicas en el ámbito local terminan teniendo presencia en los órganos regionales del partido, y 3) los resultados en las elecciones autonómicas de 1995, pero sobre todo de 1999, permite que una serie de dirigentes regionales consoliden su poder dentro de la dirección nacional. De manera que, a partir de los años noventa, las organizaciones regionales logran que las provinciales queden subordinadas a su autoridad y que sus opiniones sean tenidas en cuenta por la cúpula nacional. Evidentemente, a medida que eso va sucediendo, la incidencia del ámbito regional dentro del grupo parlamentario es mayor.

El Grupo Parlamentario Socialista no sigue la misma pauta que el popular. Aquí, según se observa en la tabla 11, el grupo mayoritario durante las dos primeras legislaturas estudiadas es el de las mujeres que cuentan con una experiencia a nivel nacional para luego ceder el testigo al nivel regional, mientras que, en la última, parece dominar el provincial. En todo caso, si hacemos un cómputo global, deberíamos decir que, al igual que sucede en el PP, las mujeres socialistas, antes de entrar a engrosar las filas del grupo parlamentario en el Congreso de los Diputados, han desempeñado cargos en el partido a nivel nacional, lo que, en principio, nos induce a atribuirles una mayor experiencia y un mayor bagaje en la arena política a nivel estatal, aunque de nuevo se viene a demostrar que, en uno y otro caso, la cúpula nacional es la que tiene la última palabra a la hora de elaborar las listas, por mucho que cualquiera de los procedimientos se vea envuelto por una aureola de democracia hacia las entidades territoriales. Por tanto, en ambos casos, la política de integración de mujeres viene instrumentada y dirigida por la propia cúpula dirigente.

Para concluir, ya sólo nos resta analizar la experiencia que tienen las mujeres en los cargos públicos. Inevitablemente, ésta se encuentra ligada, primero, a los resultados electorales que sufra el partido en los distintos comicios y, segundo, al proceso de integración de mujeres que se está llevando a cabo en ambos partidos. En este sentido, los datos de la tabla 12 corroboran nuestra hipótesis, en primer lugar, porque los buenos resultados que consigue el partido en los distintos comicios les permiten contar con un mayor número de personas que poseen una experiencia previa en el ámbito autonómico y local, 


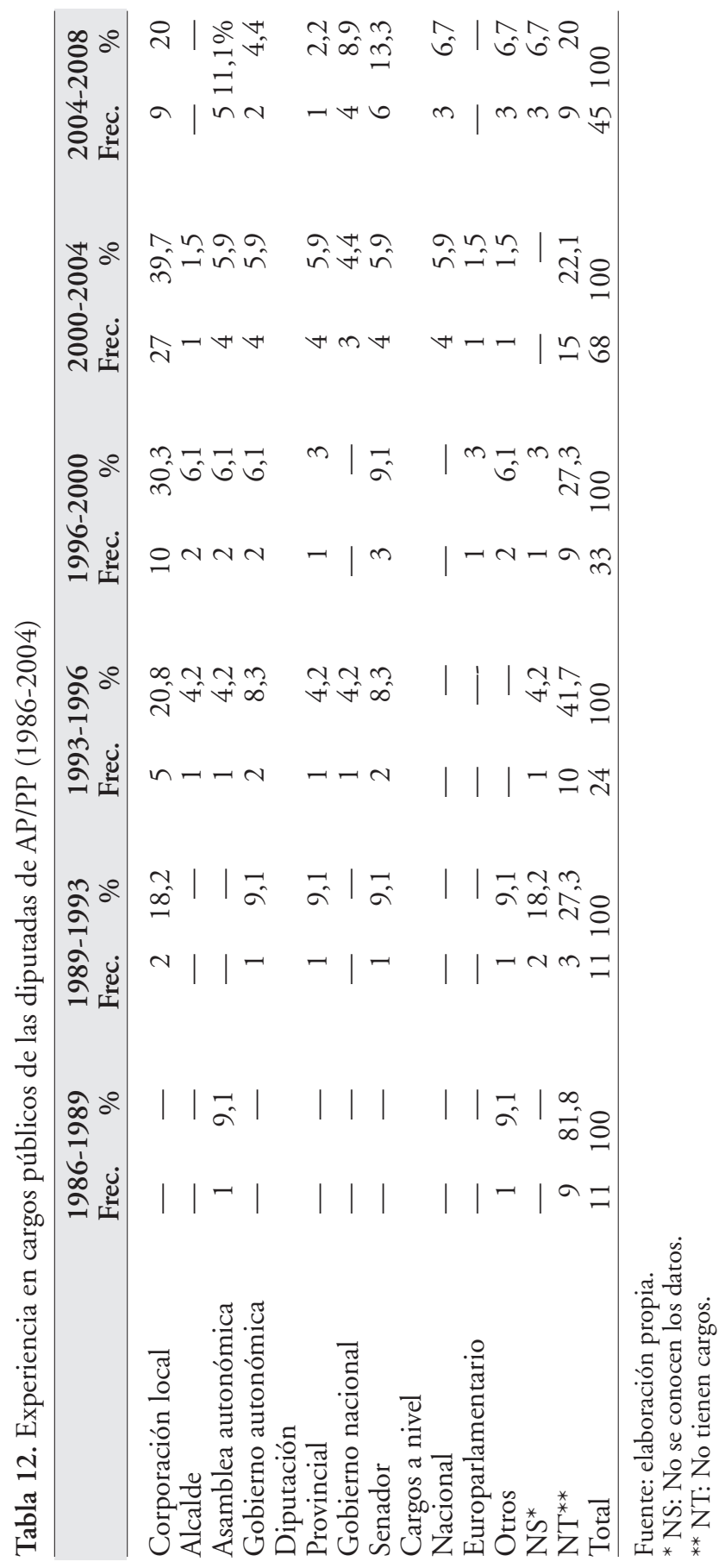


y, en segundo lugar, porque, gracias a la clara intención que muestra la cúpula dirigente por incorporar mujeres, éstas no hacen más que aumentar su presencia en el Grupo Parlamentario Popular.

Es más, si estudiamos la presente tabla, podremos concluir una cosa que ninguna otra nos ha permitido afirmar. En el ámbito en que las mujeres han tenido mayor representación ha sido a nivel local, ya que, desde las elecciones municipales de 1995, el PP ha situado a muchas de ellas encabezando las listas de importantes municipios, valgan como ejemplos: Málaga (Celia Villalobos), Cádiz (Teófila Martínez), Sevilla (Soledad Becerril), Valencia (Rita Barberá), Zaragoza (Luisa Fernanda Rudi), sólo por citar algunas. Esto les ha permitido adquirir un importante peso dentro del partido, no solamente porque han aportado votos valiosísimos, sino porque su fuerte personalidad las ha convertido en un polo de atracción indudable (Cernuda, 2000). Todos ellas, salvo la alcaldesa de la capital del Turia, han formado parte del grupo parlamentario en el Congreso de los Diputados. Soledad Becerril y Luisa Fernanda Rudi dejaron el Parlamento para desempeñar las nuevas funciones que les habían otorgado las urnas y, una vez que terminaron las mismas, volvieron a retomar su actividad parlamentaria; Celia Villalobos, en cambio, decidió compaginar ambos mandatos, y Teófila Martínez abandonó el Parlamento para iniciar una nueva carrera, primero en el Ayuntamiento y después en la Asamblea andaluza. De esta manera, las corporaciones locales se han convertido en un lugar para el rodamiento de las mujeres del partido. Las cifras que nos facilita la tabla 12 así lo demuestran: en 1993, el 25\% de las mujeres del grupo parlamentario había desempeñado alguna función en el ámbito municipal; en 1996, era el 36,4\%; en 2000, el $41,2 \%$, y en 2004, el $20 \%$.

Antes de proseguir con el análisis, deberíamos advertir, para una mejor comprensión de las tablas, que hemos tomado en consideración, al igual que en las dos anteriores, el cargo público más relevante que, a nuestro entender, ha tenido cada diputada antes de iniciarse la legislatura. La victoria electoral en las elecciones de 1996 supuso una nueva forma de incorporar a la mujer a la actividad política. En el primer ejecutivo de José María Aznar ocuparon carteras ministeriales tres mujeres: Esperanza Aguirre, Loyola de Palacio y Margarita Mariscal de Gante; en el segundo, lo hicieron: Pilar del Castillo, Celia Villalobos y Anna Maria Birulés, aunque ésta última abandonó el gobierno el 9 de julio de 2002, pero en esa remodelación entraron a formar parte del mismo otras dos mujeres: Ana de Palacio y Ana María Pastor, y el 28 de febrero de 2003 lo haría una más: Ma Elvira Rodríguez Herrer. En total, han sido nueve las mujeres que han sido ministras en las dos legislaturas en las que ha gobernado el Partido Popular, cifra nada despreciable si tenemos en consideración que, durante los tres gobiernos precedentes de Felipe González, sólo hubo cinco. De esta manera, tras alcanzar el poder, los cargos en el ejecutivo y los derivados de ejercer labores de gobierno han servido como otro punto de referencia para valorar la experiencia a nivel nacional de las mujeres del partido, aparte, naturalmente, de la posibilidad que siempre ha existido de desarrollar parte de su carrera en el Senado. 


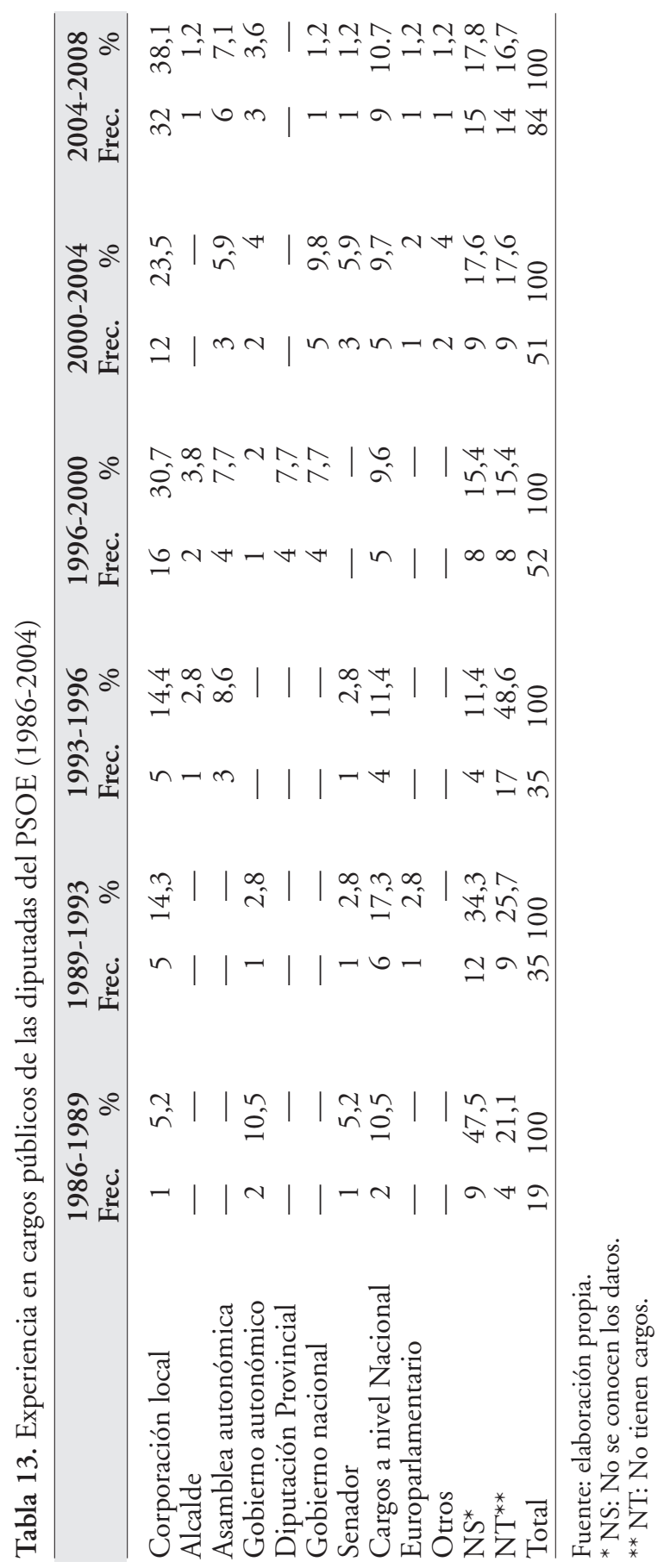


Por otra parte, los porcentajes de las mujeres que cuentan con experiencia en el ámbito autonómico se han ido incrementando progresivamente hasta la llegar al 15\% en la octava legislatura (2000-2004). La causa se debe a la política deliberada de integración que está poniendo en práctica el partido, así como al aumento de poder que han adquirido los barones regionales en sus órganos de dirección. Además, imaginamos que esta tendencia al alza se verá reforzada por la Ley de Igualdad efectiva entre mujeres y hombres aprobada por el ejecutivo socialista en el año 2007. En función de esta normativa, las mujeres tendrán que aparecer representadas al menos en un $40 \%$ de cada lista electoral. Gracias a ella, podemos afirmar que las últimas elecciones municipales y autonómicas celebradas el 27 de mayo de 2007 han dibujado unos parlamentarios más paritarios. Así, tras estas elecciones, siete asambleas autonómicas se han ajustado rigurosamente a la ley y han obtenido un $40 \%$ de representación femenina (Cortes de Baleares, Cantabria, Castilla y León, Ceuta, Melilla, Murcia y Canarias), aunque todavía continúan encontrándose por debajo de estas cifras los parlamentos de Aragón, Asturias, Navarra y Extremadura, etc.

La presencia de diputados con experiencia en el Gobierno de la Nación durante la tercera, la cuarta y la quinta legislaturas obedece a esa política de integración de personalidades de otras fuerzas de centro-derecha que ha protagonizado el partido a lo largo de estos años, dado que, hasta 1996, no se ha logrado ganar unas elecciones generales. Es lógico, por tanto, que, cuando eso sucede, el porcentaje de estos diputados se vea incrementado justo en la siguiente legislatura. Es exactamente lo mismo que ocurre con los cargos a nivel nacional. Esto vuelve a demostrar que la política de integración de las mujeres en el grupo parlamentario ha sido dirigida en un momento dado por la cúpula nacional. Por tanto, la incorporación de los hombres de la UCD viene a favorecer la profesionalización del grupo. Este hecho vuelve a corroborar nuestra hipótesis de partida: la política de incorporación de mujeres es una estrategia dirigida desde la cúpula nacional. No hay cuotas oficialmente, pero sí existe una estrategia dirigida en este sentido. Si no fuera así, lo normal sería que esta política de integración de personalidades de otras fuerzas políticas también hubiera tenido alguna repercusión en el perfil sociológico de las mujeres del grupo parlamentario.

La incorporación de mujeres en el Grupo Parlamentario Socialista, al igual que ocurre en el caso del Popular, depende de los resultados electorales y de la política de integración de mujeres que se lleve a cabo en todo momento. Pero, en este caso en particular, la influencia de la puesta en marcha de la cuota es mayor que en el anterior, dado que, en el PP, la mejora en los resultados electorales coincide con la decisión de la cúpula nacional de ir incorporando mujeres a los cargos del partido y de representación institucional. En cambio, el PSOE había cosechado unos excelentes resultados electorales antes de que se aprobara la primera medida dirigida al establecimiento de algún tipo de cuota y, sin embargo, la presencia de mujeres, por ejemplo, durante la tercera legislatura, era más bien escasa, en concreto, 19 ocuparon bancos en el Congreso de los Diputados. 
Las mujeres socialistas provienen principalmente, al igual que en el caso del PP, del ámbito local. A partir de la cuarta legislatura (1989-1993), sus porcentajes no han dejado de incrementarse hasta alcanzar, en la octava legislatura (2004-2008), el 38,1\% (ver tabla 13). Tal vez porque esa sea la esfera política donde las mujeres encuentren menos barreras a la hora de incorporarse a la vida pública, y eso que, en este espacio, las mujeres socialistas han desempeñado un papel menor que las populares, dado que aquí no ha destacado el papel de las grandes baronesas. En cuanto a los cargos de nivel nacional, ocupan el segundo lugar en el ranking. El haber ejercido labores de gobierno durante la primera etapa de la democracia puede haber influido en este hecho. Además, el desempeñar este tipo de funciones seguramente les habría abierto la puerta de la ejecutiva federal, que, en definitiva, es la que tiene la última palabra sobre la elaboración de las listas, por no hablar de la capacidad de influencia que les otorga tal posicionamiento. La política de Zapatero de incorporar a mujeres en su ejecutivo también ha repercutido en este sentido. No olvidemos que, en su primer gobierno, hubo ocho mujeres ${ }^{3}$ que ocuparon una cartera ministerial, como una manera de defender la paridad, y en el segundo, incluso integró a una mujer más ${ }^{4}$.

En el nivel autonómico, la participación de las mujeres socialistas también es importante, pero, más que asumir funciones en los ejecutivos, su papel queda reducido al de diputadas autonómicas en sus asambleas respectivas. No obstante, como podemos observar en la tabla 13, la arena autonómica ha permitido dar el salto a algunas mujeres a la política nacional, pero, sobre todo, se trata de las que proceden de aquellas autonomías donde el peso de los barones sigue siendo importante. Para concluir, solamente nos hace falta resaltar que, al igual que ocurre con las mujeres populares, el Senado y el Parlamento europeo no parecen ser unos buenos escenarios para que las mujeres socialistas den el salto a la política nacional. De todos modos, no es de extrañar, porque normalmente los partidos consideran estos dos espacios políticos como el reducto para los dinosaurios de sus organizaciones, es decir, el retiro dorado de los hombres del partido. Por tanto, de nuevo, como en el caso anterior, las mujeres que desempeñan funciones en el Congreso de los Diputados cuentan con una experiencia política principalmente desempeñada en el ámbito local.

3. Las ministras del primer ejecutivo de Zapatero son: Ma Teresa Fernández de la Vega (vicepresidenta primera y portavoz del Gobierno), Magdalena Álvarez Arza (ministra de Fomento), Elena Espinosa Mangana (ministra de Agricultura, Pesca y Alimentación), Carmen Calvo Poyato (ministra de Cultura), Elena Salgado Méndez (ministra de Sanidad y Consumo), Cristina Narbona Ruiz (ministra de Medio Ambiente) y Ma Antonia Trujillo (ministra de la Vivienda).

4. Las ministras del segundo ejecutivo de Zapatero son: $M^{a}$ Teresa Fernández de la Vega (vicepresidenta primera y portavoz del Gobierno), Carmen Chacón (ministra de Defensa), Mercedes Cabrera Calvo-Sotelo (ministra de Educación, Política Social y Deporte), Elena Espinosa Mangana (ministra de Medio Ambiente), Cristina Garmendia (ministra de Innovación), Bibiana Aído (ministra de Igualdad), Magdalena Álvarez (ministra de Fomento), Elena Salgado (ministra de Administraciones Públicas), Bernat Soria Escoms (ministra de Sanidad y Consumo) y Beatriz Corredor Sierra (ministra de Vivienda). 


\section{Conclusiones}

La conclusión más clara que podemos sacar después de haber realizado el siguiente análisis es que todos los partidos están integrando paulatinamente a las mujeres, tanto en sus órganos de dirección, como en los niveles institucionales donde obtienen representación. El PP es el único partido español de ámbito nacional que no ha establecido estatutariamente un sistema de "cuotas", pero, pese a ello, ha decidido ir incorporando mujeres, tanto en sus órganos de gobierno como en sus grupos parlamentarios, aunque las cifras que arrojan, por lo menos en el ámbito parlamentario, todavía están lejos de los parámetros de una igualdad de sexos. Sólo a partir de la quinta legislatura (19931996) logran superar la barrera del $10 \%$, porque hasta entonces la participación de la mujer en el Grupo Parlamentario Popular se encontraba por debajo de estos parámetros. Únicamente en la octava legislatura (2004-2008) su presencia ha llegado a alcanzar un porcentaje que ronda el 30\%. Sin embargo, se encuentra lejos del de otros partidos, como el socialista, que sí han apostado por una política de paridad basada en un sistema de «cuotas», aunque todavía no ha terminado por dar cumplimiento a la Ley de igualdad.

No obstante, como hemos podido comprobar desde la llegada de José María Aznar a la presidencia del partido, se ha apostado claramente por fomentar la presencia de mujeres en la vida organizativa y política de la formación. Gracias a ello, cada vez son más las que participan en la vida política, pero, sin embargo, pese al crecimiento cuantitativo que está experimentando, aún son pocas las que desempeñan puestos de gran responsabilidad. Esto nos puede inducir a pensar que las iniciativas de democracia paritaria que están llevando a cabo los partidos guardan más bien correlación con la necesidad imperiosa de hacerse eco de una importante demanda de las sociedades modernas, como demuestra el hecho de que sea necesario establecer sistemas de cuotas para garantizar su presencia en las organizaciones políticas, o que, por ejemplo, todavía sean escasas las medidas de conciliación familiar que se están implantado.

En todo caso, como decimos, las mujeres poco a poco se están incorporando a la vida política. En este sentido, habría que recalcar que los partidos políticos que han regulado estatutariamente su participación han obtenido mejores resultados que los que no cuentan con ningún tipo de regulación al respecto. Como hemos podido comprobar, en los partidos como el PP, que no han establecido ningún sistema de "cuotas", las mujeres han visto incrementada su presencia en la organización y en sus ámbitos de representación, pero en menor volumen que el PSOE, donde sí existen medidas a favor de la discriminación positiva, aunque, como venimos diciendo a lo largo de todo este artículo, el PP ha llevado una política de incorporación de mujeres deliberada y encubierta. Un dato que nos puede inducir a pensar así es la edad media que presentan las mujeres del grupo parlamentario en comparación con la de sus compañeros, porque, si la práctica habitual hubiera sido incorporar a mujeres a sus filas, aunque hubiese sido en un número reducido, habría cierta representa- 
ción de ellas en alguno de los grupos de edad que superan los 55 años, como sucede con los hombres. La juventud de las mujeres del Grupo Popular está íntimamente ligada a su nivel de estudios. La mayoría de ellas, al igual que ocurre con el PSOE, ha cursado estudios universitarios. Si la incorporación de mujeres se hubiera hecho sin intencionalidad, lo lógico sería que, al igual que antes mencionábamos que debería haber habido mujeres con mayor edad en el grupo parlamentario, también hubiera sido lógico que el porcentaje con estudios primarios hubiera sido mayor.

En cuanto a su procedencia, poca cosa podemos decir, salvo que las mujeres siguen prácticamente las mismas pautas que las del Grupo Parlamentario Socialista, es decir, provienen mayoritariamente de la Administración y de la docencia, aunque las socialistas añaden un campo más: la abogacía. El estudio de su procedencia no nos aporta ningún dato significativo o concluyente sobre una política de paridad articulada por la cúpula dirigente. En cambio, sí lo hacen los datos que se refieren a la experiencia de las diputadas con cargos en el partido. Las mujeres populares han desempeñado mayoritariamente funciones en dos ámbitos: el nacional, hasta la quinta legislatura (19931996), y el regional, a partir de la sexta legislatura (1996-2000). Estos datos indican de nuevo que ha existido una política de «cuotas» articulada desde la cúpula nacional, porque, en un primer momento, las mujeres proceden de los órganos nacionales, y después, cuando, a partir de 1995, los barones regionales adquieren peso a nivel nacional, las mujeres provienen de ese ámbito. Prácticamente lo mismo sucede en el PSOE, donde sí existe una política de cuota, lo que nos demuestra de nuevo que la incorporación de mujeres al Grupo Popular es una política orquestada desde la propia cúpula nacional del partido. Respecto al bagaje político con el que parecen contar las mujeres populares es, al igual que en el caso socialista, su experiencia en el ámbito local. Se trata de otra nueva prueba que nos induce a pensar que la estrategia del PP es una política deliberada de ir incorporando mujeres a la vida parlamentaria, dada cuenta que es precisamente el ámbito municipal el mejor lugar para que las mujeres puedan foguearse en política, ya que es donde encuentran menores dificultades para ello. En todo caso, gracias al estudio de estas variables, hemos podido determinar las pautas de la política de integración de las mujeres en el partido y el perfil sociológico que presentan las mismas. Es más, si tuviéramos que exponer cuál es el arquetipo de las mujeres del PP, tendríamos que decir que son mayoritariamente jóvenes, licenciadas, provenientes de la Administración Pública y del campo de la docencia, con experiencia en el partido en el ámbito nacional y regional, y que han desempeñado cargos preferentemente en el ámbito municipal. Un perfil similar al que presentan las mujeres socialistas. La única diferencia entre ambas formaciones es que las mujeres del partido que ha optado por un sistema de cuotas, el PSOE, disfrutan de una mayor presencia en el Congreso de los Diputados que el que no, el PP. Pero, viendo las pautas seguidas por el PP, no nos cabe duda de que este partido también ha apostado por un sistema de cuotas encubierto. 
Los cambios que se han producido en sus programas en torno a las cuestiones de género también corroboran nuestra hipótesis de partida. Desde la llegada de Aznar a la presidencia del partido, el PP ha modificado una buena parte de sus propuestas relacionadas con los temas que afectan a las mujeres. Así, por ejemplo, en la sexta legislatura (1996-2000), no retiró la legislación sobre el aborto, como había amenazado hacer en 1985, votó a favor de la comercialización de la píldora abortiva RU-486, etc. Este cambio de actitud le supuso al PP las críticas de la Iglesia católica española, que, durante la campaña electoral de 2000, pidió de forma explícita a los católicos que no votaran a los partidos que no defendieran el derecho a la vida, incluyendo entre ellos al PP (Ruiz Jiménez, 2006). La razón obedece principalmente a que el cambio de discurso respondió inicialmente a una estrategia instrumental y electoral, al igual que la política de integración, pero el propio éxito de la misma le impidió dar marcha atrás.

Para terminar, sólo nos resta mencionar que las medidas de discriminación positiva resultan ser favorables para incrementar el número de mujeres que se han incorporado a la vida política, pero consideramos que no debería ser necesario si realmente existiera una voluntad para ello. Es más, creemos que la práctica habitual debería basarse en integrar a aquellas personas que resultaran ser válidas, con independencia de su sexo. $\mathrm{Y}$ es ahí hacia donde debemos caminar. No se trata tanto de establecer cuotas, sino de apostar por el respeto a la meritocracia. Además, para que las mujeres puedan desempeñar sus funciones en igualdad de condiciones con los hombres, se les deben proporcionar medidas que favorezcan la conciliación con el hogar, dado que, en muchas ocasiones, la falta de ellas se ha convertido en otra barrera infranqueable para la asunción de mayores competencias. No olvidemos que las mujeres no sólo tienen una obligación laboral, sino también familiar, y ésta, normalmente, les condiciona más que a los hombres. En este sentido, el partido socialista acaba de aprobar una ley de igualdad que vela tanto por aspectos cuantitativos como cualitativos, aunque, tras un año de vigencia, no se han obtenido los resultados esperados. Electoralmente, no se ha producido ningún avance. Es más, el propio PSOE tendrá tres diputadas menos en esta legislatura. A nivel laboral, por ejemplo, las mujeres continúan cobrando un $5 \%$ menos que sus compañeros e incluso todavía hay consejos de dirección de empresas que no cuentan con una sola mujer.

\section{Bibliografía}

ÁGuila, Alicia del y LLANos, Beatriz (2008). «Cuotas, sistema electoral y prácticas partidarias. Clave de los avances y barreras a la participación política de la mujer en la región andina». En: FonTAINe, Arturo; LARROUlet, Cristian; NAVARreTE, Jorge y WaLKER, Ignacio (ed.). Reforma de los partidos político en Chile. Santiago de Chile: PNUD, CEP, Libertad y Desarrollo, Proyectamérica y CIEPLAN, 251/272.

BAER, Denise L. (1993). «Political Parties: The missing variable in women and politics research». Political Research Quartely, 43, 547-576. 
Bou, Marc (2003). «La participación de las mujeres en la política». Boletín del Instituto Internacional de Gobernabilidad Política en Cataluña. [http://www.americalatinagenera.org/documentos/publicaciones/doc_74_La-participacion-de-las-mujeresen-la-politica.doc]

BukER, A. Eloise (1999). Talking feminist politics. Nueva York: Rowman \& Littlefield Publishers.

Buvinic, Mayra y RozA, Vivien (2004). La mujer, la politica y el futuro democrático de América Latina. Washington DC: Banco Interamericano de Desarrollo.

CAStro, Raúl (1995). El sucesor. Madrid: Espasa Calpe.

CAUL, Miki (1999). "Women's representation in parliament: The role of political parties». Party Politics, 5 (1), 79-98.

Cernuda, Pilar (2000). La mujer en la política: El largo camino hacia la igualdad. Barcelona: Plaza Janés Editores.

GARCÍA-GuERETA RodríGuEZ, Elena Ma (2001). Factores externos e internos en la transformación de los partidos políticos: el caso del PP. Madrid: Instituto Juan March de Estudios e Investigaciones. Centro de Estudios Avanzados en Ciencias Sociales.

HTun, Mala N. y Jones, Mark P. (2002). «Engendering the right to participate in decision-making: Electoral quotas and women's leadership in Latin America». En: Craske, Nikki y MolyneuX, Maxine (ed.). Gender and the politics of rights and democracy in Latin America. Nueva York: Palgrave, 32-56.

KoHN, W. S. (1980). Women in national legislatures: A comparative study of six countries. Nueva York: Praeger.

KROOK, Mona Lena (2005). Politicizing representation: Campaigns for candidate gender quotas worldwide. Columbia: Columbia University.

- (2006a). «Gender quotas, norms, and politics». Politics \& Gender, 2 (1), 110-118.

- (2006b). «Reforming representation: The diffusion of candidate gender quotas worldwide». Politics \& Gender, 2 (3), 303-327.

LARrEA, Raúl (1999). «El PSOE tiene más chicas que el PP». Cambio 16, 12 de febrero, 22-24.

López NieTo, Lourdes (1997). «El Parlamento 1977-1996». En: AlCÁNTARA, Manuel y Martínez, Antonia (eds.). Política y Gobierno en España. Valencia: Tirant lo Blanch: 189-210.

MonTERO, José Ramón (1989). «Los fracasos políticos y electorales de la derecha española: Alianza Popular, 1976-1987». En: TeZANOS, José Félix; COTARElo, Ramón y BLAS, Andrés de (coord.). La transición democrática española. Madrid: Sistema.

OJEDA RiverA, Rosa Icela (2006). "Las cuotas de género para el empoderamiento de las mujeres». El Cotidiano, julio-agosto, 21.

Ruiz JimÉnEZ, Antonia Ma (2002). Mecanismos del cambio ideológico e introducción de políticas de género en partidos conservadores: el caso de AP/PP en España en perspectiva comparada. Madrid: Instituto Juan March de Estudios e Investigaciones.

- (2006). De la necesidad, virtud. La transformación "feminista» del Partido Popular en perspectiva comparada (1977-2004). Madrid: Centro de Estudios Políticos y Constitucionales.

RulE, Wilma (1994). «Parliaments of, by and for the people: Except for women?». En: Rule, Wilma y Zimmerman, Joseph Francis (ed.). Electoral systems in comparative perspective. Their impact on women and minorities. Westport: Greenwood press.

SÁNCHEZ MEDERO, Gema (2003). El_papel de las mujeres en dos grandes partidos españoles: PP y PSOE. Ponencia presentada en el VI Congreso Español de Ciencia Política y de la Administración, celebrado en Barcelona el 18-20 de septiembre. 
- (2007a). «El papel de las mujeres en los dos grandes partidos españoles». Revista Cultura y Politica, (28), 91-123.

- (2007b). «Liderazgo, representación parlamentaria y análisis de las interacciones (1989-2004): El caso del PP». Madrid: Tesis Doctoral de la Universidad Complutense.

- (2008). «El papel de las mujeres en la política española: el caso del PSOE». Revista de Estudos Feministas, 16 (3), 91-123.

SHILS, E. (1975). Center and periphery. Chicago: Chicago University Press.

VERGE, Tania (2005). «Mujer y partidos políticos en España: las estrategias de los partidos y su impacto institucional, 1978-2004». En: VII Congreso Español de Ciencia Politica y de la Administración, "Democracia y Buen Gobierno", Madrid, 21 al 23 de septiembre.

- (2006). «Mujer y partidos políticos en España: Las estrategias de los partidos políticos y su impacto institucional, 1978-2004». REIS, 115, 165-196. 